\title{
DESIGN-VALUE IN THE PLATFORM APPROACH
}

\author{
Duncan W. Maxwell ${ }^{1}$ and Mathew Aitchison ${ }^{2}$
}

\begin{abstract}
Lean production has responded to low-level customisation, but for residential construction, earlier customer input is required. The development of the 'platform approach' to industrialised house building has enabled high-level masscustomisation. Focus has been applied to 'hard' improvements regarding production efficiency, with less emphasis on 'soft' values associated with the intangible nature of design. Platform-thinking has demonstrated that new possibilities are emerging which may enable producers of industrialised housing to effectively deliver designvalue to end-users.

This paper contributes to the developing platform approach, by investigating design-value for industrialised house building from an architectural perspective. Through an understanding of the product platform approach developed within the Swedish context, selected case-studies from outside construction demonstrate the possibilities that the platform-thinking concept holds, to address the research question; how can design-value be achieved in industrialised house building?

Much design-value originates from interaction between designer and user, which has been overlooked in the development of the platform approach, yet by considering its conceptual basis of platform-thinking, new possibilities emerge for the delivery of design-value in product and process. The findings will enhance the development of platforms for industrialised house building.
\end{abstract}

Keywords: Lean design, platforms, platform-thinking, design-value, architecture.

\section{INTRODUCTION}

Architectural engagement with prefabrication has had a chequered history, resulting in a late-twentieth century division of engagements with industrialised construction: that of architecture, and that of the broader housing industry (Davies 2005). Prior to this division, in establishing a motto for the Bauhaus School of Design, Walter Gropius viewed architecture's engagement with industry as a fundamental aspect of modern design: 'Art and Technology - a New Unity'. In this unity, Gropius saw architecture as a profession primarily of integration, positing that 'technology did not need art, but that art needed technology', and consequently modern designers should seek links between art, science, technology and society (Mindrup 2014).

Seeking these links and integration, Le Corbusier's book, Le Modulor, established a series of measurements to enhance standardisation and minimise "obstacles, sweeping them away before the majesty of the rule" (Le Corbusier 1954, p.112). Le Corbusier envisioned the architect mediating the relationship between humans and their environment, and hoped that these rules would allow domestic design to be elevated such that "a house fulfilling all its practical functions can go beyond strict utilitarianism and attain the dignity of a palace..." (Le Corbusier 1954, p.113). Le Corbusier's thinking sets

PhD Candidate, Innovation in Applied Design Lab, Faculty of Architecture, Design and Planning, The University of Sydney, Sydney, Australia, duncan.maxwell@sydney.edu.au

2 Associate Professor, Innovation in Applied Design Lab, Faculty of Architecture, Design and Planning, The University of Sydney, Sydney, Australia, m.aitchison@sydney.edu.au 
an important benchmark in considering the design-value of industrialised architecture beyond functionalism, to benefit society and provide improved living conditions for occupants. For most of the modernist architects concerned with industrialised construction, efficiency of production and design-flexibility were the primary markers of design-value, rather than this integration and mediation of contextual factors. Today, this legacy extends beyond the profession of architecture, to inform industrialised house builders' methods, inhibiting the realisation of design-value. As Anne Beim (2004) states, this "pragmatic interpretation of industrialization seems to be the predominant feature of contemporary construction, despite the industry's inherent potentials." To bridge this division, and ensure improved client and producer outcomes, greater focus must be placed on designvalue in industrialised house building.

\section{LEAN AND VALUE}

'Lean' has long associated value with waste (Womack et al. 2007). Lean production's value focus seeks to minimise waste in processes and the resulting product's material usage, with the dominant lean construction value perspective being that of Koskela's (2000) transformation-flow-value theory. Where value of the product is concerned, there has been an emphasis on materiality and buildability, achieving value in design through modularisation (Björnfot \& Stehn 2004). Beyond modularisation and buildability, Stephen Emmitt (2011) reflects on a significant knowledge gap in lean production with regards the management of design to create value, during the early phases of projects, when significant design input is required to achieve maximum value for the customer. Integrated Project Delivery methods are helping to fill this void, together with Target Value Design (TVD), yet the basis of TVD sees value and the result of collaboration from an economic perspective (Zimina et al. 2012), while Integrated Project Delivery research has had a strong focus on the contractor's perspective rather than the role of the designer (Volker \& Klein 2010). Salvatierra Garrido and Pasquire (2011) surveyed the range of value perspectives that exist in lean construction. Their assertion is that a more holistic understanding of value is required due to its objective, subjective, relative, context dependant and dynamic nature. Into this broad understanding of value is inserted consideration of design-value to contribute a more holistic perspective of value for lean construction.

Acknowledging the variety of value perspectives that exist within Lean, this paper limits its discussion to focus on design-value, distinct from these pre-established value perspectives. Gann (2010) notes that there has been little effort to establish design quality metrics in construction, and research into this area has revealed inherent difficulties as design in its nature reveals subjective, intangible qualities. This places consideration of design-value, as a soft factor counter to lean's often hard, technical, cost and efficiency value perspective. Steiner and Harmon (2009) determined that an holistic approach to customer value is determined by a 'value platform', with value increasing from a hierarchy that is based on a product layer (physical product), has a service layer added on top, and which is topped off by an intangibles layer which interacts with both product and service and which comprises: knowledge, emotion and experience. It is the author's assertion that lean theory has investigated both the product and service layers of the value platform, yet little research has been conducted into the intangible layer, and this is the realm of designvalue. 


\section{Design-VALUE}

Academics and practitioners alike have often struggled to pin down a definition for the value that design brings to projects, because it deals with these sensual intangibles, is highly subjective, and subject to the changeability of taste and fashion. Dewulf and Van Meel (2004) summarise how mid-twentieth century understanding of design-value was brought about by a 'soft' user-focus, yet these factors proved difficult to communicate outside of academia. This failure to communicate led the quality debate to harder, more quantifiable ground by the 1980s where design-value was to be entwined with the field of architectural science, notably indoor environmental quality (IEQ). By the early 2000s, a research project was commissioned by the Construction Industry Council, to establish a Design Quality Indicator Tool (Markus 2010). This project sought to balance design research endeavours of the time that were considering productivity and efficiency in construction, by seeking the definition of design-value which would incorporate softer values and assess the impact and quality of design solutions (Gann et al. 2010). The debate remains open as to the effectiveness and validity of results (Dewulf \& van Meel 2004), though this project remains one of the few design quality assessment tools to be used in the construction market and embraces design's qualitative nature seeking a balance between subjective and objective views (Markus 2010).

Henry Plummer has described the affect that architecture can have on the human existence. Plummer considers contemporary architecture in the built form to suffer from two threats, both of which are familiar to the consideration of design-value in industrialised construction; utilitarianism and spectatorism (Plummer 2016). The former reduces design to an economic commodity based on ease of production and which standardises human engagement, while the latter strives to make design entertaining and novel, ultimately overpowering the audience. The design-value of projects utilising industrialised construction must seek to finely balance these viewpoints, and seek to impact on the human senses in the way that traditional construction can.

Continuing to consider design-value from a sensual point of view, Lisa Heschong's book 'Thermal Delight in Architecture' (1979) laid out four fundamental qualities that good design must possess: necessity, delight, affection and sacredness. It is perhaps no coincidence that Heschong's research has been highly influential in architectural science circles which, has been a field which has not shied away from seeking to define architectural quality. Heschong's thesis was that thermal qualities play an essential role in our understanding of space, and can be used to think about design's impact on all senses: the necessity of our fundamental physiology, surprise causing delightful sensory stimulation, social rhythms reinforcing an affectionate emotional engagement, and the transmission of cultural knowledge described by sacredness.

Robert Woods Kennedy, an architect and critic divided residential design-value into two dominant aspects in his book of 1953, The House and the Art of its Design (Kennedy 1953). Kennedy considered residential design-value as either physical or process-based and as reliant on people and context. Seeking to balance of product and process designvalue, Andrea Campioli (2011) found that a hard, traditional, and technological view of innovation in construction had isolated design from construction. This divide, as with the split pursuit of architecture and industrialised construction, has led architects to design novel and innovative solutions that are very specific to the design problem posed rather than being transferrable (a pre-requisite for design of industrialised house building). Developing a combined product and process view of design-value, led Campioli to establish that there are two opportunities for improvement of architectural quality when 
applied to industrialised construction. One based on horizontal integration and focused on product improvement (familiar to many integrated house production companies), while the other seeks to establish networks of relationships across the supply chain to enhance the process and product. This paper contests that this networked vision for design-value fits with the concept of platform-thinking.

\section{PlatForms AND InDUSTRIALISED HOUSE BUILDING}

\subsection{The Platform Approach to Industrialised House Building}

In Sweden, following the lessons of mass production, enhanced by the Lean manufacturing philosophy, companies are building industrially built housing projects effectively and efficiently. Through collaboration with academia, Swedish builders have been developing a 'platform approach' for industrialised house building. With its origins in product-design and manufacture, the platform approach constitutes shared product assets consisting of components, processes, knowledge and relationships, which can be configured to deliver a range of product outcomes (Robertson \& Ulrich 1998; Lehnerd \& Meyer 1997)

These industrialised house building platforms are enabling more efficient design and delivery processes to be realised (Jansson \& Viklund 2015), knowledge management practices to be refined (Jansson et al. 2016), as well as seeking opportunities for modularisation of the physical components to achieve effective mass-customisation (Johnsson et al. 2013). The platforms range from those which are highly constrained, or closed, to those which are flexible and open. Closed platforms in Sweden see customisation practiced through the arrangement of combinations of pre-designed apartment layouts, or the arrangement of pre-engineered modules to create a diversity of apartment sizes (Jansson \& Viklund 2015). Open platforms see design tasks broken down and supported by visual planning techniques, where the pre-engineering occurs in wall build-ups which are configured to custom apartment designs (Lidelöw et al. 2015).

Platform approaches are reliant upon a range of contextual (place) factors and actors' (people) experience, this variability means that it is not enough to transplant one mode of thinking directly from one culture to another. A broad, open and global perspective is required to tackle these differences and leads to the concept of platform-thinking.

\subsection{Platform-thinking for Industrialised House Building}

Lean-thinking has driven its value focus from the perspective of the customer, to which the producer must then deliver. 'Platform-thinking' extends and complements this value focus to include both the consumer and producer's perspective, connected through a 'platform'.

Platform-thinking, as a concept, links producers and consumers more directly than traditional businesses, altering how an offering and market are perceived and managed. A platform-based business model contrasts with traditional business models which were typically based on 'pipes' (Choudary et al. 2016). Pipe businesses add value sequentially through a chain of interactions; by contrast the emerging platform business model creates an ecosystem of interactions between producers and consumers which add value in an integrated manner. Today, the platform-thinking approach to value creation has a clear and profound impact on the consideration of design-value for industrialised construction, due to its ability to connect production and end-users through a design-focused platform.

Businesses that utilise platform-thinking are being increasingly understood from a virtual, information-technology perspective, for example AirBnb and Uber. When we 
consider the physical realm of production, the implications of platform-thinking are less widely discussed. Yet, the platform approach to industrialised construction has a number of similarities with the emerging concept of platform-thinking. Despite their contrasting physical-virtual environments. Choudary (2015) determined that platforms operate at three levels: a networked community where interactions take place, infrastructure which allows and supports interactions and data generated by and supporting future interactions. These three levels of platform-based business operations can be compared against Robertson and Ulrich's (1998) definition of platform assets. 'Infrastructure' may be seen as the components and processes, the 'data' as knowledge, while the 'network-communitymarketplace' is an expanded definition of the people and relationships.

The platform-thinking concept is also based on three logics: connecting, sharing and integrating (Eloranta \& Turunen 2016), enabling a community of users to create value through new external interactions rather than existing internal business processes (Choudary et al. 2016). This community of users becomes the definition of a platform business, when compared to traditional business models which were defined by assets which were either resource or knowledge-based. With regards design-value, it is therefore less important that a platform business have a design (resource) 'ready-to-go', but rather have a network of users who can define and create design-value through interaction (utilising knowledge).

\subsection{Platform-thinking and Design-value}

As it is not yet clear the impact that platform-thinking may have on the design-value outcomes of industrialised house building, it is relevant to examine how platform-thinking is impacting on design and production organisations that are outside of construction, yet still deal with production, creativity and innovation.

\subsubsection{Manufacturing: Quirky}

'Quirky' is a self-described invention platform, which specialises in the design and ultimately facilitates the manufacture of products. The platform acts to facilitate interactions between people with product ideas (generating the conceptual idea), contributors (giving product feedback) and skilled experts (documenting or rendering the idea and feedback). This can happen openly on the platform, or collaborators can agree to meet within closed groups. Collaborators agree to share portions of 'influence', being a cut of the final product revenue. Product ideas that are worked on between collaborators, are then chosen by community members to be pitched to brand partners for product development and manufacture.

Despite its chequered history (Quirky's start up team filed for bankruptcy during 2015, but was bought and relaunched by investors), Quirky demonstrates that a design-led, manufacturing platform is possible, drawing together diverse expertise in the form of a community of designers and manufacturers to add design-value through open collaboration in new and innovative means compared to traditional product design processes, connecting producers and designers with consumers.

\subsubsection{Music: Splice}

The music industry has embraced platform-thinking through a consumer-focus, as a means of tackling the growth of piracy brought about by an historic industry-focus, finally finding a degree of stability with the likes of Spotify and Apple Music. Yet there is argument that this newfound stability and consumer-focus has been at the expense of the industry, leaving a void for a balanced approach to emerge. 
'Splice' has emerged to fill this void. A collaborative music creation network designed to allow musicians to showcase, distribute and collaborate on projects. Producers can share music projects in source format suitable for remixing and collaboration on popular music editing software, or simply to gather feedback from the broad global community. Operating on a subscription basis, Splice has enabled travelling musicians to gain access to a studio in the cloud, or for collaboration to occur across continents. Music collaboration platforms are by no means unique, Splice competes with a range of other platforms which focus on producers. By allowing producers to showcase their projects directly to consumers, there is potential that these collaborative platforms may end up disrupting the purely consumer-focused 'listening' platforms. Splice demonstrates the importance of balance in platform design to create value for both producer and consumer. The shifts in focus which created these listening, and now distribution music platforms, demonstrates the parallels that exist through construction's historic supplier focus (Saxon 2010), which presents a similar possibility for disruption. For construction, this is especially important, as "A value-centred industry, which works for all its stakeholders, will transcend the limits of construction as currently defined" (Saxon 2010, p.335).

\subsubsection{Innovation: Nosco}

Increasingly, dedicated platforms for innovation are being utilised by business to generate and receive feedback on design ideas, and encourage greater collaboration. 'Nosco' is a social platform, which has been used by the likes of Allianz, Reebok and Volkswagen for product development, improvement, and knowledge management. The platform operates at four levels: social, workflow, measure and manage. At the social level, the Nosco platform encourages collaboration, communication and knowledge-sharing through the posting of design ideas, comments and voting for what users consider worthy or useful innovation. Workflow allows the platform participants to manage design ideas through processes which are easily repeated and refined. Analytical data is increasingly important to companies, and the Measurement aspect of the platform allows companies to understand where in their organisation ideas are being generated and how they are being received. Through the management component of the platform, ideas and knowledge can be effectively controlled and communicated around the organisation utilising the platform.

Social media has at times been maligned, yet this social view of value generation which focuses on the management of flows of information between platform users has provided clear benefit. No longer need the design review be a rare occurrence or overly time consuming, instead through the utilisation of platform-thinking, design ideas can be continually tested and refined, not just during early stages but also receiving feedback from all levels of the construction supply chain.

\section{CONCLUSION}

Koskela and Vrijhoef (Koskela \& Vrijhoef 2001) discussed the importance of developing a new theory for construction that would promote innovation to tackle construction's cost issues, variability and unstable supply chains, along with ingrained methods of working and knowledge management practices which hold the industry back. There is potential that platform-thinking may enable a response to some of these issues, especially with a greater design-value focus.

A focus on process design-value, has shown that greater clarity in the communication of the value of design can be achieved through an integrated, holistic perspective, resulting in design ideas which are transferrable. Product design-value must also be accommodated 
by the incorporation of softer, more sensual values, transporting design-value beyond efficiency and production of process and product.

While the platform approach being utilised by industrialised house builders has enabled greater design flexibility and mass customisation opportunities to be realised, the design-value outcomes of industrialised house building remains an open question. Many Swedish companies have achieved outstanding results in terms of lean, efficient production systems delivered through a platform approach, yet through this paper designvalue has been shown to be a key consideration in the definition of a more holistic industrialised house building industry. Investigating the concept of platform-thinking has shown the possibilities that exist when design-value is considered with greater connectivity, sharing, and integration of producers and consumers. Potentially part of a new theory for lean construction, platform-thinking case studies have shown the concept to enable collaboration, open pathways of communication, balance perspectives, create free flows of information, as well as instituting effective knowledge management procedures. Platform-thinking businesses create an ecosystem of producers and customers, to effectively create design-value, and demonstrate the potential of a more holistic industrialised house building industry to bridge the divide that exists between architecture and production.

\section{REFERENCES}

Beim, A., (2004). Tectonic Visions in Architecture, Copenhagen, Denmark: Kunstakademiets Arkitektskole Forlag.

Björnfot, A. \& Stehn, L., (2004). Industrialization of Construction - A Lean Modular Approach. 12th Annual Conference of the International Group for Lean Construction. Helsingør, Denmark.

Campioli, A., (2011). "Architectural quality: innovation, technological research and design". TECHNE, 1(1): 62-69

Choudary, S.P., Parker, G.G. \& Van Alystne, M., (2015). Platform Scale, Platform Thinking Labs.

Choudary, S.P., Van Alystne, M. \& Parker, G.G., (2016). "Pipelines, Platforms, and the New Rules of Strategy". Harvard Business Review: 54-62.

Davies, C., (2005). The Prefabricated Home, London: Reaktion Books.

Dewulf, G. \& van Meel, J., (2004). "Sense and nonsense of measuring design quality". Building Research \& Information, 32(3): 247-250.

Eloranta, V. \& Turunen, T., (2016). "Platforms in service-driven manufacturing: Leveraging complexity by connecting, sharing, and integrating". Industrial Marketing Management, 55(C): 178-186.

Emmitt, S., (2011). "Lean Design Management". Architectural Engineering and Design Management, 7(2): 67-69.

Gann, D., Salter, A. \& Whyte, J., (2010). "Design Quality Indicator as a tool for thinking". Building Research \& Information, 31(5): 318-333.

Heschong, L., (1979). Thermal Delight in Architecture, Cambridge, Massachusetts, USA: The MIT Press.

Jansson, G. \& Viklund, E., (2015). "Advancement of Platform Development in Industrialised Building". Procedia Economics and Finance, 21: 461-468.

Jansson, G., Viklund, E. \& Lidelöw, H., (2016). "Design management using knowledge innovation and visual planning". Automation in construction, 72(3):.330-337. 
Johnsson, H., Jansson, G. \& Jensen, P., (2013). "Modularization in a housing platform for mass customization" 29th Annual ARCOM Conference, Reading, UK: 91-100

Kennedy, R.W., (1953). The House and The Art of its Design, Huntington, New York: Robert E. Krieger Publishing Co.

Koskela, L., (2000). An exploration towards a production theory and its application to construction. Helsinki, Finland: VTT Publications.

Koskela, L. \& Vrijhoef, R., (2001). "Is the current theory of construction a hindrance to innovation?" Building Research \& Information, 29(3): 197-207.

Le Corbusier, (1954). Le Modulor 2nd ed., London: Faber and Faber Ltd.

Lehnerd, A.P. \& Meyer, M.H., (1997). The Power of Product Platforms, New York, NY: Simon and Schuster.

Lidelöw, H., Jansson, G. \& Viklund, E., (2015). Design Breakdown in Industrialized Construction: Supporting Lean Manufacturing. 1st MOC Summit, Edmonton, Canada: 255-262.

Markus, T.A., (2010). "Lessons from the Design Quality Indicator". Building Research \& Information, 31(5): 399-405.

Mindrup, M., (2014). "Translations of Material to Technology in Bauhaus Architecture". Wolkenkuckucksheim, Internationale Zeitschrift zur Theorie der Architektur, 19(33): 161-172.

Plummer, H., (2016). The Experience of Architecture, London: Thames \& Hudson.

Robertson, D. \& Ulrich, K., (1998). "Planning for Product Platforms". Sloan Management Review, 39(4): 19-31.

Salvatierra Garrido, J. \& Pasquire, C., (2011). "Value theory in lean construction" Journal of Financial Management of Property and Construction. 16 (1): 8-18.

Saxon, R., (2010). "The industry "formerly known as construction": an industry view of the Fairclough Review". Building Research \& Information, 30(5): 334-337.

Steiner, F. \& Harmon, R., (2009). "The impact of intangible value on the design and marketing of new products and services: An exploratory approach". Portland International Conference on Management of Engineering \& Technology: 2066-2079.

Volker, L. \& Klein, R., (2010). "Architect Participation in Integrated Project Delivery: the Future Mainspring of Architectural Design Firms?" Gestão \& Tecnologia de Projetos, 5(3): 39-58.

Womack, J.P., Jones, D.T. \& Roos, D., (2007). The Machine That Changed the World, New York, NY: Simon and Schuster.

Zimina, D., Ballard, G. \& Pasquire, C., (2012). "Target value design: using collaboration and a lean approach to reduce construction cost". Construction Management and Economics, 30(5): 383-398. 